THE HOSPITATS OF IONDON. No. VII.

BY DR. CORMACK AND DR. SRMPLE, ABSISTED BY NUMEROUS REPORTERS.

\title{
HOSPITAL FOR CONSUMPTION AND DISEASES OF THE
} CHEST, AT BROMPTON.

Consulting Physiciang - Dr. Forbes, F.R.S., Dr. C. J. B. Williams, F.R.S., Dr. Walshe.

Physiorars - Dr. Hamilton Roe, Dr. Theophilus Thompson, F.R.S., Dr. Cursham.

Assigtant-Physicians-Dr. R. P. Cotton, Dr. R. Quain, Dr. J. Hutchinson. Consulting-Suraeon-W. Fergusson, Esq., F.R.S.

Resident Medicat Officer-Vertue Edwards, Esq.

It has always been a maxim-and a very proper one-with the general hospitals of our metropolis, to do the greatest possible amount of good to the greatest possible number of individuals; and this has led unavoidably to the rejection of certain chronic and other affections, ordinarily looked upon as incurable, from their portals. Consumption having been necessarily included in this list, phthisical patients have long required some institution where medical skill might be sedulously devoted to their relief, and, after this may have failed, where tenderness and care might soothe their passage to the grave. In the hospital at Brompton, these objects are combined-both an hospital and an asylum are offered to the consumptive sufferer; whilst an opportunity is afforded, for the first time in this country, for extended scientific and practical observation upon a disease which annually destroys at least one in every 300 persons.

In the patronage given to this charity, England has set a brilliant example to other nations; for, notwithstanding the universality of consumption, no other hospital exists for its reception, except at Rome, where that of St. John in Laterano, containing 400 beds, admits females affected with phthisis; but it is not exclusively devoted to this disease, a certain proportion of the beds being employed for cases of fever.

The benevolent scheme of founding an hospital for consumption, in this country, was first entertained by Philip Rose, Esq., and communicated to several friends; and these gentlemen have now the satisfaction of seeing the fruit of their early efforts in the permanent establishment of the present institution.

In the year 1842 , the charity commenced its operations in a private house in Chelsea, capable of containing twenty patients, and having a small outpatient department. But it was not destined to a long continuance in such comparative insignificance, and in so limited a sphere of action. In the summer of 1844, H.R.H. Prince Albert laid the foundation stone of the present building, which was completed in 1846.

The style of the building is worthy of remark, since it was the first attempt to adapt the collegiate and domestic architecture of England, as it prevailed towards the close of the fifteenth century, to the purposes of a modern hospital. It probably suggested itself to the mind of Mr. Francis, the architect, that something of a more cheering and inviting character than the plain and massive edifices of the present day was desirable for an hospital which was intended as the future scene of a somewhat unusual share of gloom. The architecture is Tudor. The walls are of red brick, with blue headers, interlaced in pattern; and Caen stone dressings are applied to the gables, windows, buttresses, etc. In form, the building resembles the letter $\mathbf{H}$, consisting of a centre and two wings ; one wing, however, yet remains unfinished. In the quadrangle facing the high road, the plainness of the walls is relieved 
by oriel windows, buttresses, and battlements, and a tower with octagon turret rises from the centre; the doorway is deeply recessed and its top battlemented. The centre of the building is chiefly devoted to domestic and business offices; and the two wings are principally intended for male and female patients respectively. The wards differ in size, being constructed to receive from two to ten patients in each ; they are light and lofty, and afford upon an average 950 cubic feet of air to every patient. The total accommodation, at the present time, extends to forty-five beds for males, and the same number for females; but the hospital will contain, when completed, not less than two hundred patients. All the window-sashes are fitted with double panes of glass, for the preservation of warmth and the avoidance of drafts ; and there is a large corridor upon each gallery, well warmed and ventilated, where the patients can take exercise when unable to walk in the grounds attached to the hospital.

The mode of heating and ventilating the building occupied from the very first the anxious attention of the managing committee. The whole subject was referred to Dr. Arnott, under whose direction the present arrangement was carried out. It consists of an apparatus for propelling air warmed to a regulated temperature through the entire building. The warming and ventilating chamber is in the basement of the building under the central tower, and contains :-

1. A steam-engine for working the pump.

2. A pump for drawing in the external air, and propelling it through the building.

3. A series of copper plates arranged in a large chamber, so constructed that hot water passes freely between them, and imparts its heat to the air immediately after it has escaped from the puinp.

4. Channels for conveying the heated air to every part of the building.

Two thousand one hundred and sixty cubic feet of air per minute are thus drawn from the exterior of the building, and forced between the heated copper plates, which are placed between the pump and the main channel. The admission of the air thus warmed into the wards and corridors, is regulated by a number of openings close to the floor, whilst its escape is provided for by one or more of Dr. Arnott's valves introduced into the chimneys. The fireplaces are not absolutely required for this arrangement, and therefore are generally kept closed.

Such is a brief sketch of this ingenious method of combining the heating and ventilating processes. A difference of opinion, however, has long existed as to its efficiency. Whether or not this is attributable to a defective manner of pursuing it, is equally disputed; and the whole subject of ventilation to be applied to the new wing is, as yet, under consideration.

The chapel, which is an elegant specimen of ecclesiastical architecture, built from the designs and under the direction of Mr. Lamb, was munificently founded by the Rev. Sir Henry Foulis, Bart., and consecrated in 1850. This building is likewise of the style of church architecture as it prevailed about the end of the fifteenth century. It is divided into nave, transepts, and chancel. The roofs are of arched wood framing, and the spandrels filled with tracery. The sittings are divided into classes; those in the chancel are for presidents or clergy ; those next the transepts, for the governors and officers of the institution; and behind these are the seats for the paticnts. The whole of the seats are cushioned. All the fittings are of oak, and in appropriate positions are decorated with the arms and crest of the founder. Most of the win dows have been filled with stained glass, presented by patrons of the institution. The chapel is approached by a corridor from the entrance hall, which, together with the chapel itself, is warmed by hot water.

Having described the general purposes and character of the building, at a greater length than may have been usual in this series of hospital records, but in a manner which could scarcely have been abridged, and may noi, 
perhaps, be deemed uninteresting, in consequence of its novelty, it remains that we should add some remarks upon its medical reputation as an hospital and school.

We might point to the "First Medical Report of the Hospital for Consumption" as an evidence of the zeal and ability of its medical officers. This publication, which has received the general approbation of the profession, and which was noticed in this JoukN $1 \mathrm{~L}$ ( upon the statistics of the hospital, and resulted from the combined efforts of the physicians and assistant-physicians, - a result of harmony and good feeling amongst colleagues, of which we hope, in coming years, to see many similar examples, not only in this, but in other hospitals. Observations upon a still larger scale, and embracing points not yet treated of, are steadily progressing at Brompton, and we look forward with no little pleasure to the appearance of the Second Medical Report.

In order to supply materials for these reports, a very perfect system of registration of cases, embracing their history, progress, and treatment, is carried on by two resident clinical assistants upon the in-patients; and a complete statistical record of the out-patients is likewise adopted by the assistant-physicians.

The following tables, derived from the hospital books, illustrate the kind and extent of these observations.

TABLE I. IN-PATIENTS. OBBERVATIONB.

\begin{tabular}{|c|c|c|c|c|c|c|c|c|c|c|c|c|c|c|c|c|}
\hline 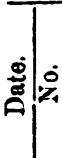 & 旁 & $\mid$ & 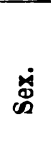 & $\begin{array}{l}\dot{2} \\
\Delta \\
\dot{0} \\
\dot{2}\end{array}$ & 总离 & 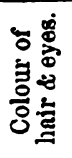 & 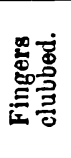 & 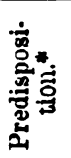 & 营 & 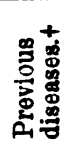 & 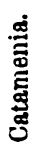 & 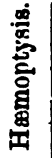 & 兽 & 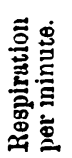 & 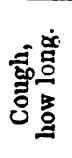 & 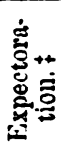 \\
\hline & & & & & & & & & & & & & & & & \\
\hline
\end{tabular}

\begin{tabular}{|c|c|c|c|c|c|c|c|c|c|c|c|c|}
\hline 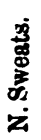 & 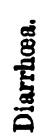 & 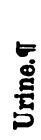 & 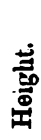 & 莡 & 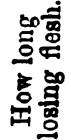 & 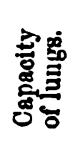 & $\begin{array}{l}\dot{\Xi} \\
\stackrel{8}{0} \\
\dot{0} \\
\dot{0}\end{array}$ & 苞㻤 & 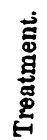 & 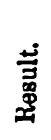 & 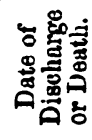 & 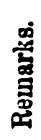 \\
\hline & & & & & & & & & & & & \\
\hline
\end{tabular}

- Under this head are arranged the various grades of relationship, viz., father, mother, etc. + This is divided into "Nature of" and "How long since."

I Includes " character" and " quantity."

Under this is given the Sp. gr., Quantity, Acid, A kaline.

TABLE II. OUT-PATIENTS.

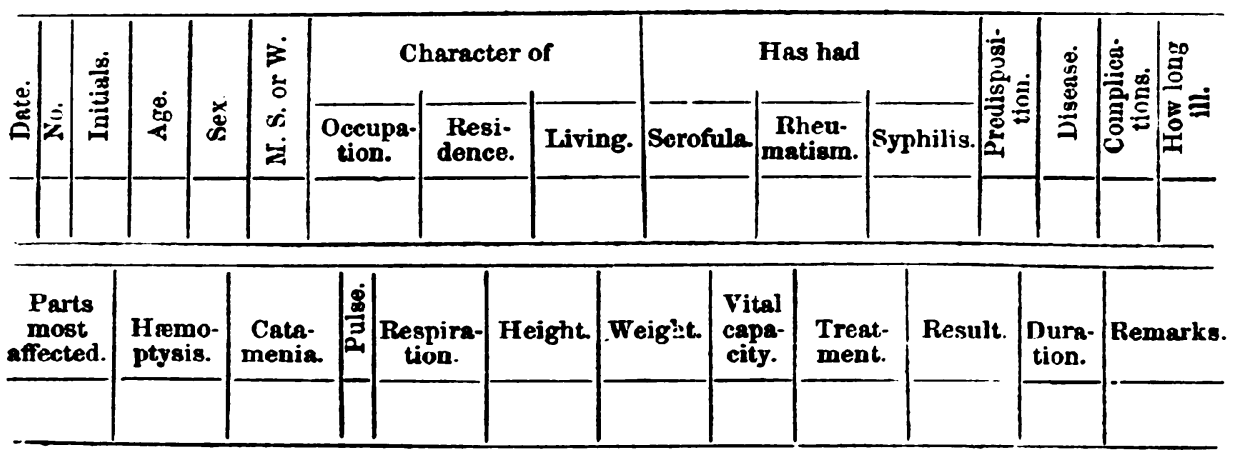

VOT. III. 
Careful and extended notice is also taken of the post-mortem appearances of fatial cases; a leaf of the book kept for this purpose is here transcribed.

TABLE III.

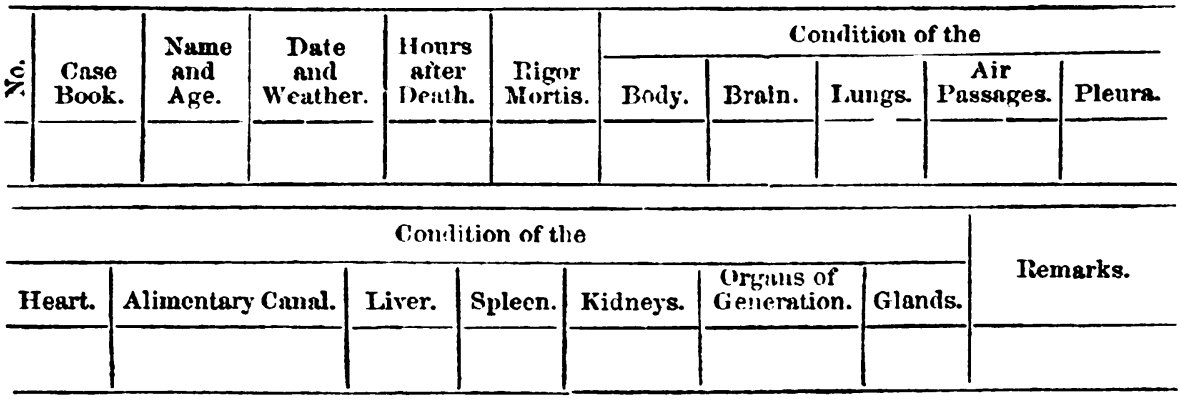

A pathological muscum is in progress of formation, which must ultimately contribute important aid to the study not only of phthisis, but of other tuberculous diseases.

Pupils are admitted to the hospital practice, and some of the medical off:cers have already delivered lectures upon the diagnosis and treatment of phthisis ; and hopes are entertained of thus rendering the charity useful as a school for the study of diseases of the chest.

Since the opening of the new building, 1,524 in-patients have been admitted; and between 3,000) and 4,000 persons attend annually as out-patients.

The in-patients are chiefly the subjects of phthisis; but sufferers from other diseases of the chest are frequently admitted. No selection is made of cases, so that phthisis may be studied in all its different phases. The period for patients remaining in the hospital is limited to three months ; but cases which have arrived at the very last stage, and must soon close in death, are not dismissed at the expiration of this time; and the physicians are privileged to recommend an extension of residence to any particular cases, by which the purposes either of charity or medical science are likely to be advanced. The out-patients are not so limited as to the nature of their cases, any form of real or supposed thoracic disease being considered within the operation of that department: heart affections, dyspepsia, bronchitis, asthma, etc., are consequently common amongst them, and afford an excellent field for comparative diagnosis.

Cod-liver oil is pretty generally administered, in some form or other, by all the medical officers, whose good opinion of its effects, as originally expressed in their Report, still remains unshaken. This cannot be better shown than by the extent to which it is employed. In the year $1849, £ 260$ were expended in this medicine alone; and during the first quarter of the present year, 156 gallons were disposed of. The best pale-coloured oil only is used ; none of an inferior quality being now ever received into the hospital. During its administration, the patients are carcfully and periodically weighed ; and the results compared with the other symptoms. Some of the physicians have employed other animal and vegetable oils; and will, it is hoped, inform the profession of their comparative effects, when such have been sufficiently tested.

In closing this account of the Brompton Hospital for Consumption, we have only to express our approbation of the scientific and charitable zeal evinced in its operations. On future occasions, we hope to be able to place before the profession occasional reports upon the interesting points which must ever be presenting themselves to the notice of the physicians. 


\section{THE CITY OF LONDON HOSPITAL FOR DISEASES OF THE CHEST.}

[With two Woodcuts.]

Is our last number (p. 688), we mentioned that the first stonc of this Hospital was laid by his Royal Highness Prince Albert, on Wednesday the 25th of June last. We now propose to give a brief notice of the history and eljects of the institution.

The City of London Hospital for Diseases of the Chest was established in June 1848 ; and differs in some degree in its objects from the Hospital for Consumption at Brompton, being established for the treatment of all forms of pulmonary and cardiac disease; while the hospital at Brompton was originally intended to be limited to the reception of cases of consumption. This rule, however, as we have stated, is not rigidly acted upon at Brompton. We think the promoters of the new hospital have done wisely, in deciding to admit to its benefits persons labouring under all forms of affection of the chest. Owing to the great prevalence of consumption in this country, the number of persons applying for relief, to any institution specially devoted to the treatment of that disease, will almost necessarily exceed the amount of accommodation; and thus many persons will constantly be waiting for admission, and comparatively few will be received till after the period has gone by during which medical treatment can be of much avail : and we can conceive few things more disheartening, both to the patients and their medical attendants, than to see constantly around them only those who are sinking rapidly under incurable discase, or whose sufferings are only susceptible of very partial alleriation.

Of late years, the number of institutions specially devoted to the treatment of particular forms of discase have too much increased; but, within just limits, we conceive that the practice is conducive to the advancement of medical science. Such institutions should, however, be limited to the reception of cases which require, for various reasons, to be placed apart from the mass of cases in a general hospital, or of which the cure can be best conducted in wards specially adapted for the purpose. They should embrace a suficiently wide field of observation; and the attention of the medical men connected with them should not be too exclusively directed to the study of the class of diseases, for the relief of which thcy are established. The former of these requirements is, we think, fulfilled in reference to the institution in question; and of the seven medical men attached to it, five are connected with large general hospitals. The out-patient department has as yet only been in operation; but we observe by the reports that already 9,000 persons have been under treatment, and that the daily attendance of patients varies from 70 to 140 ; facts which sufficiently attest the want which existed for such an institution in the eastern portion of the metropolis. Though the hospital has been so short a time in operation, it has already been deprived by death of the services of two of its medical officers, Mr. Aston Key, the consulting surgeon, and Dr. Allen Williams, one of the acting-physicians. The present medical staff is as follows :

Consulting Physicians. Dr. Babington, and Dr. Jeffreson.

Phrsiciass. Dr. Peacock, Dr. Bentley, Dr. Risdon Bennett, and Dr. Birkett.

Surgeon. Mr. Hilton.

It would be premature at present to speak of the institution as a field for medical study ; but, with its present large number of patients, the opportunities for investigating the various forms of disease of the respiratory and circulatory organs must be considerable ; and when the hospital is completed, its sphere of usefulness will be greatly extended. A system of statistical registration has been in use since the first opening of the dispensary, and will in time yield valuable results; and there already exists a collection of 


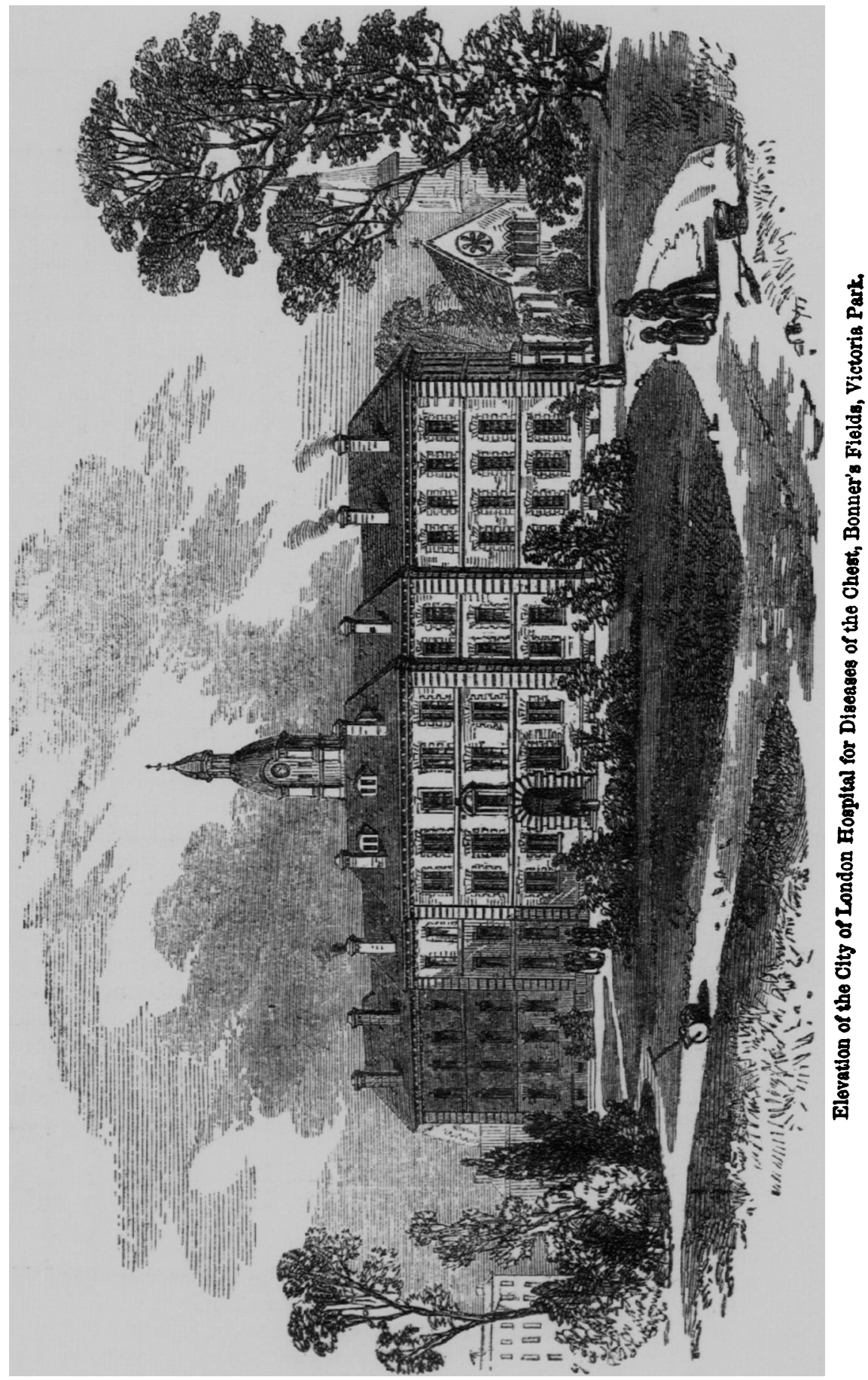


CITY OF LONDON HOSPITAL FOR DISEASES OF THE CHEST. 757

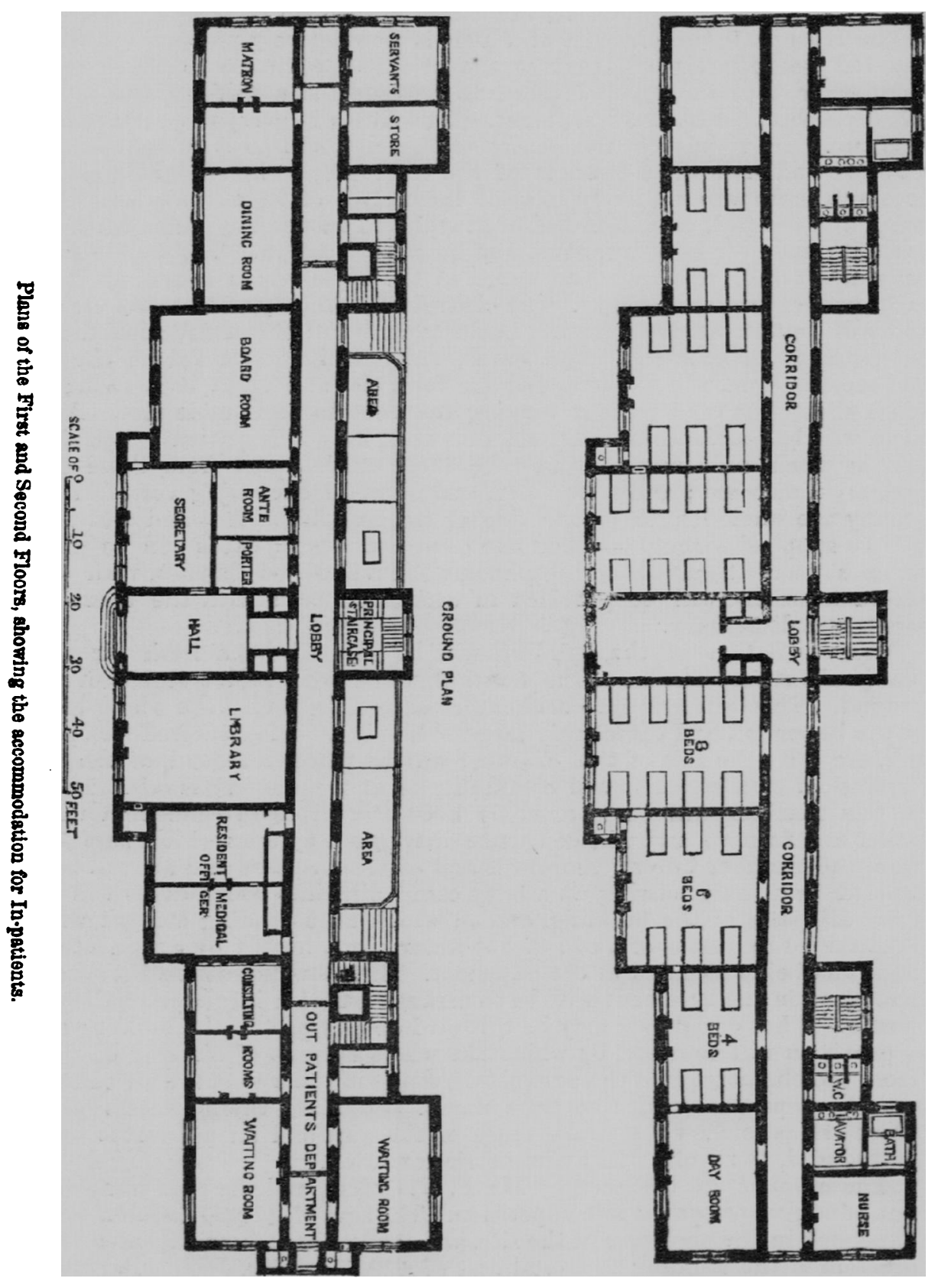


preparations illustrative of cardiac and pulmonary affections, and which, though small, conterins soine rare and interesting specimens of disease. We trust that when fully in operation, the institution will form an useful school for the study of the particular class of diseases for the relief of which it has been established, and that it may conduce, along with the sister institution at Brompton, to the advancement of our knowledge of those affections.

The Hospitar, the erection of which is now actively proceeding, will be situated immediately adjacent to the principal entrance to the Victoria Park, where a plot of ground, upwards of three and a half acres in extent, has been obtained from Government. This site is in every respect a favourable one. Its vicinity to the centre of the city, and to some of the most crowded and unhealthy districts of the metropolis, will render it easy of access to those who are likely to avail themselves of its advantages; while, being well drained, on a deep bed of gravel, and immediately adjacent to the park, it must ever be a dry, open, and healthy situation. The building has been designed of red brick and stone, in the style which prevailed at the early part of the last century. The central portion only will be first erected, and will contain wards for eighty patients, and full accommodation for the out-patients' department. The wards, which will be situated on the first and second floors, will be arranged for four, six, and eight beds each; the space allotted to each patient varying from 800 to 1200 cubic feet. A day room will be provided for each set of wards, in which patients capable of leaving their beds may sit and take their meals, apart from those more severely indisposed ; and wide, lofty, and cheerful exercising corridors will occupy the whole length of one side of the building. Ilot and cold water will be supplied throughout, and two complete sets of baths will be placed on each floor. Separate waiting rooms for males and females, with other accommodations, will be provided in connexion both with the consulting rooms and dispensary.

The ventilation of the building will be effected by a fresh air shaft, placed about fifty fect from the hospital, and raised twelve feet above the ground. This will lead into a chamber extending under the whole length of the basement, and sufficiently large to admit of being entered for cleansing, etc. By the side of this chamber will be placed a second, of the same dimension, with which it will communicate at frequent intervals. The air in this chamber will be warmed by hot-water pipes in connexion with a boiler and furnace, and will be thence distriliuted by flues which pass direct from the chamber into all the wards and corridors. The foul air will be extracted by a shaft passing up a lofty campanile, into which ducts will open from all parts of the building, and in which an ascending current will be maintained by means of a coil of hot-water pipes, heated by a separate furnace and boiler situated in the basement. The communications between the chambers in the basement will be so arranged, that a larger or smaller proportion of hot or cold air may be thrown into any part of the building; and a provision will be made, by which the whole current of air may be passed from the chambers into the exhausting shaft, in order that the air chambers may be kept pure and free from damp. Standard thermometers will be placed so as to show the temperature of the air; and an apparatus will be introduced, to regulate its hygrometric condition.

The hospital was designed by Mr. F. W. Ordish, and the plan was selected out of twelve presented in competition. The sum of $£ 1,200$ has already been expended in the enclosure of the site, and tenders have been accepted for the erection of the building at a total cost of $£ 10,732$. Mr. Joseph Paxton, the architect of the Crystal Palace, has furnished a design for a Sanatorium, to be erceted at the back of the hospital, of glass and iron, ind used as an exereising garden by the patients during cold weather. It is proposed to consist of an elegant building, 212 feet long, 72 wide, and $45 \mathrm{high}$, with a circular roof, on the ridge and valley principle. 'The interior will be divided 
by a partition, 12 feet high, into two equal portions, having separate communications with the hospital, so that the male and female patients may take exercise at the same time. During cold weather, the air will be admitted by flues, running under the floor and up the partition. The requisite degree of warmth will be obtained from coils of hot water-pipe placed in the partition; and at the top of the building there will be a series of apertures, through which a portion of the air will escape, while another portion being cooled by its contact with the glass, will sink and re-enter the air-flues, so that the fresh air will be gradually diffused over all parts of the interior of the building, and a constant and agrecable current will be maintained, while all direct or cold druughts will be avoided. In summer, the warming apparatus will of course not be required, but ample ventilation will result from the effect of the sun upon the glass. The fresh air will then be admitted at the sides of the building, and in front of the apertures will be placed a screen, which, while it will interrupt the direct current of the air, and cause it to diffuse itself over the interior, will afford support to the roof. It is proposed to regulate, by a special apparatus, the amount of moisture to be contained in the air, both during summer and winter, and the conservatory will be stocked with plants which will flourish in the atmosphere maintained. The cost of the erection of the sanatorium is estimated by Mr. Paxton at $\$ 4000$.

We do not suppose that the managing committee of the hospital will be disposed to take any part at present in the carrying out of $\mathbf{M r}$. Paxton's suggestions, nor would it indeed be desirable for them to do so till the hospital is advancing towards completion; but we hope the medical officers will give the plans their attentive consideration, and be prepared to urge upon the committee the erection of the sanatorium so soon as the financial condition of the charity will admit. For ourselves, we think Mr. Paxton's proposition, if carried out, would materially increase the means of usefulness of the institution. Among the many persons who in this country suffer from consumption, or other chronic pulmonary diseases, there are indeed very few who can afford to spend the winter at Malta, Madeira, or the south-west coast of our own island; and in the inferior grades of society, any change is often unattainable ; and thus it too frequently happens, that complaints which, under favourable circumstances, are rcadily and completely curable, become, from too early exposure to the vicissitudes of our climate, or to the fruitful sources of disease which abound in the homes and workshops of the poor, either the cause of permanent indisposition, or of premature death. 'To all persons so circumstanced, the opportunity of resorting, during the cold weather, to a large and cheerful building, in which a pleasant exercising temperature will be maintained, and plants and other objects of interest will be placed, must certainly be very preferable to being constantly confined to their own rooms, provided, however, that the patients be not exposed to the external temperature in going or returning, for otherwise the result would more probably be injurious than beneficial. To the poor, the combination of a well adapted hospital, with a sanatorium of the description suggested by Mr. Paxton, will, we believe, be of great advantage, and we therefore sincerely hope that the plan may be carried out, and the patients of the new hospital be so placed in the circumstances most conducive to their entire restoration to health. In the treatment of consumption, and other chronic diseases, the employment of means calculated to invigorate the powers of the system, und to cheor and refresh the mind, are not less important than the use of direct remedial agents. 